\section{Pruning Date and Cane Density Affect Primocane Development and Yield of 'Autumn Bliss' Red Raspberry}

\section{Pedro B. Oliveira}

Departamento de Produção Agrícola, Estação Agronómica Nacional, Av. da República, 2784-505 Oeiras, Portugal

\section{Cristina M. Oliveira ${ }^{2}$}

Instituto Superior de Agronomia, Technical University of Lisbon, 1349-018 Lisboa, Portugal

\author{
António A. Monteiro ${ }^{3}$ \\ Instituto Superior de Agronomia, Technical University of Lisbon, 1349-018 \\ Lisboa, Portugal
}

Additional index words. light microclimate, nonheated greenhouse, off-season production, photosynthesis, Rubus idaeus

Abstract. The aim of this study was to determine the effects of date of summer pruning and cane densities on growth and fruiting characteristics of the raspberry (Rubus idaeus) plant. Three summer-pruning dates (early, middle, and late July) and four cane densities $(8,16,24$, and 32 canes $/ \mathrm{m}$ row) were imposed to the greenhouse-grown primocane-fruiting raspberry 'Autumn Bliss' in 2 consecutive years (1994 and 1995). A higher light microclimate and $\mathrm{CO}_{2}$ assimilation rate were measured within the canopy at the lowest density. Some compensation

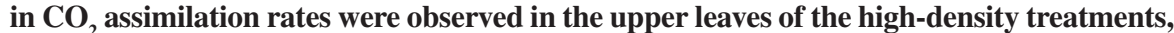
probably in response to low light. Delayed pruning decreased yield per cane and per row. The highest yields per cane were always observed at the lowest cane density. Densities of $\mathbf{1 6}$ and 24 canes $/ \mathrm{m}$ produced the highest fruit yield. Light conditions appeared to be the most important environmental factor affecting plant productivity. Fruit were a weaker sink than roots; therefore, the role of carbohydrate reserves should be investigated.

The raspberry (Rubusidaeus) plant is perennial with canes that can be managed as annual or biennial fruiting. In primocane-fruiting red raspberries flower initiation begins at the end of summer promoting a first crop on curren year canes. Flower initiation can be controlled naturally by the environment alone (Dale and Daubeny, 1987; Hudson, 1958; Williams, 1959), by interactions between genotype and environment (Dale and Daubeny, 1985; Privé et al., 1993a), or by cultural practices (Oliveira et al., 2002; Percival et al., 1998; Trinka and Pritts, 1992). Physiological studies showed that the timing of floral initiation in red raspberries is regulated by air temperature (Hoover et al., 1989), vigor (Crandall et al., 1974), and degree of light interception (Braun and Garth, 1984). Under limiting temperature and light conditions, primocane-fruiting can be suppressed or delayed until the following spring (Oliveira et al., 1996).

The red raspberry plant is considered a shade-intolerant species (Whitney, 1982). Adventitious shoots or root suckers increase

Received for publication 19Nov. 2002. Accepted for publication 9 June 2003. This work was supported by Fundação para a Ciência e Tecnologia, Programa Ciência BD/2814/93, Portugal. The authors gratefully acknowledge Marvin P. Pritts for critical review of this manuscript.

${ }^{1}$ Research assistant, corresponding author; e-mail pnbo@mail.telepac.pt.

${ }^{2}$ Associate professor.

${ }^{3}$ Professor. intracane light competition and can cause a serious problem in a primocane fruiting crop. Cane density must be adjusted to allow good light penetration into the canopy, especially in southerly locations where cane densities tend to be greater, probably due to high root zone temperature (Privé et al., 1993b).

In summer-fruiting cultivars, shading severely affects yield, but increasing light penetration into the canopy does not increase yield in the bearing year (Braun and Garth, 1984). Fernandez and Pritts (1996) showed that yields in the current year are partly determined by growing conditions in the previous year and is conditioned by the carbohydrate storage capacity of roots and the amount of primocane production. Available light (Hoover et al., 1988), self-shading (Wright and Waister, 1982), dry weight partitioning (Popenoe, 1994), and the degree of sink demand during fruiting (Fernandez and Pritts, 1994) are also important contributing factors to yield. mum yield is fairy constant, despite differences in the environment, and can be obtained with 15 canes/m (Dale, 1989). Primocane growth and yield can be manipulated by pruning date and intensity of the cane removed (Oliveira et al., 1998). Percival et al. (1996) studying the influence of irradiance, $\mathrm{CO}$ concentration and temperature on whole-plant net $\mathrm{CO}_{2}$ exchange rate documented the importance of optimizing light interception and distribution within the raspberry canopy, suggesting that shaded leaves
Fruiting cane density required to give maxi- should be kept to a minimum. Under mild winter climatic conditions, a 2-week delay in primocane pruning at ground level in July decreased fruit yield by $50 \%$ during the fall to winter period (Oliveira et al., 1996).

Within-plant competition and compensation is a less studied subject but can also contribute to differences in yield since competition between developing first year canes does exist (Dale, 1989). Pruning intensity should be adapted to the primocane fruiting cultivar to maximize first year yield. Fruit yield of 'Autumn Bliss' primocanes cut in July at ground level was delayed by 8 weeks and reduced by $50 \%$ compared with pruning at 10 nodes (Oliveira et al., 1998). Pruning date is also critical in canes pruned at ten nodes because delaying summer pruning reduces fruit yield (Oliveira et al., 1999). In all experiments conducted by Oliveira et al., yield was reduced because there were fewer fruit per lateral.

The objective of this research was to determine whether changing primocane cane density could enhance yield during the fall to winter period by altering competition for light. If light was the limiting factor in late raspberry production then an optimum cane density for a particular summer pruning date should exist.

\section{Materials and Methods}

Plants of primocane fruiting cultivar ' $\mathrm{Au}$ tumn Bliss' were planted in March 1993 in a sandy soil inside a nonheated greenhouse $(3.5 \mathrm{~m}$ high, $13.0 \mathrm{~m}$ wide, and $30.0 \mathrm{~m}$ long, with lateral and roof ventilation). The experimental farm was located at the southwestern coast of Portugal $\left(37^{\circ}\right.$ latitude $\left.\mathrm{N}\right), 4.0 \mathrm{~km}$ from the ocean and at 106 meters of altitude, under a mild winter climate (Monteiro and Portas, 1986). Rows were $1.6 \mathrm{~m}$ apart, and a $\mathrm{V}$ trellis system $(0.4 \mathrm{~m}$ at the base and $0.7 \mathrm{~m}$ at the top) was used to support the canes. Drip irrigation, fertigation and pest control chemicals were applied according to commercial practice.

Pruning treatments consisted of cutting spring-emerged primocanes at ground level on three different dates: 1, 15, and 29 July 1994 and 3, 17, and 31 July 1995. Cane density treatments were imposed by thinning primocanes (emerged from crown buds) one month after pruning dates when canes were $0.6 \mathrm{~m}$ in height. Cane densities were adjusted to $8,16,24$, and 32 canes per meter row on all dates. Linear densities translated to $5,10,15$, and 20 canes $/ \mathrm{m}^{2}$ assuming a row width of $1.6 \mathrm{~m}$. All primocanes were cut to the ground level at the end of the harvest in 1994. After the first year, primocanes were allowed to grow during next spring without thinning to assure root carbohydrate accumulation before treatments were again imposed in July 1995.

The experiment was established as a spiltplot design with four replications on 2 consecutive years, 1994 and 1995; pruning dates were the main plots and densities the subplots. To assure uniformity was maintained guard rows were established on each side of the greenhouse and a $6.0-\mathrm{m}$ border on both ends. Each subplot was four meter long. All data were collected in one meter at the center of each subplot. Data were subjected to analysis of variance, and the linear 


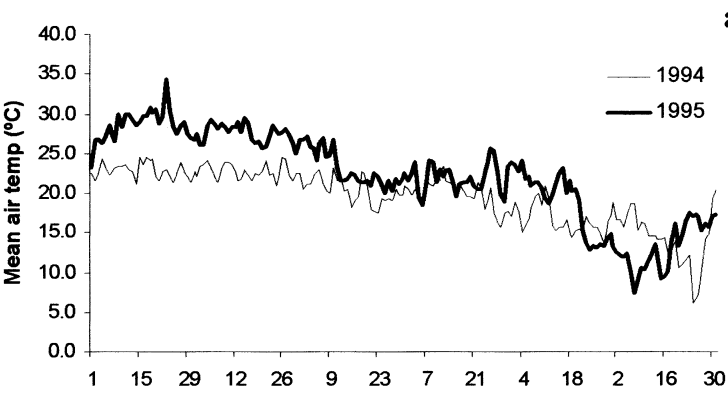

July July July Aug Aug Sep Sep Oct Oct Nov Nov Dec Dec Dec

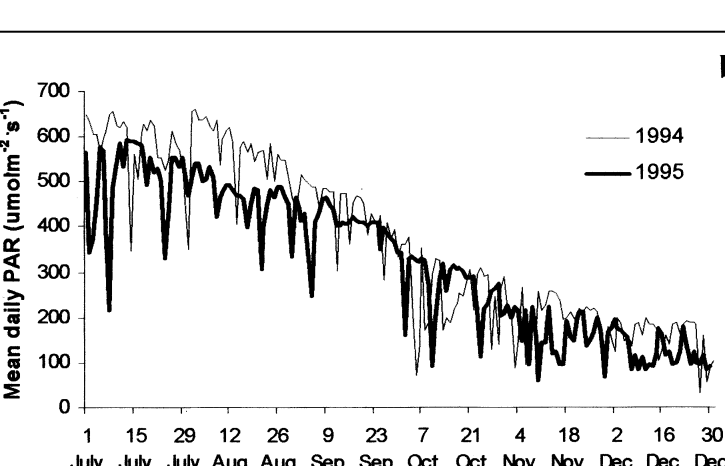

Air temperature ranged from 15 to $25^{\circ} \mathrm{C}$ during the vegetative growth period in 1994 and was considerably higher in July and August in 1995 (Fig. 1a). A second warmer period also was observed in November 1995. In 1994, from July to October, soil temperature was almost constant (20 to $25^{\circ} \mathrm{C}$ ) but it was higher in 1995 with peaks in August and November.

Irradiation $(P A R)$ showed the same pattern in 1994 and 1995 b but was consistently higher in the first 3 months of the experiment in 1994 (Fig 1b). In the 1995 experiment, irradiation was under 600 $\mu \mathrm{mol} \cdot \mathrm{m}^{-2} \cdot \mathrm{s}^{-1}$, the required threshold for light saturation during the fall to winter period (Percival et al., 1996).

Primocane density control. One month after pruning there were no significant differences in total above ground dry weight $\left(\mathrm{g} \cdot \mathrm{m}^{-1}\right.$ of row) across the three pruning dates in either year. The

Fig. 1. Greenhouse environment: (a) mean air temperature $\left({ }^{\circ} \mathrm{C}\right)$ at $1.5 \mathrm{~m}$ and $(\mathbf{b})$ mean daily PAR $\left(\mu \mathrm{mol} \cdot \mathrm{m}^{-2} \cdot \mathrm{s}^{-1}\right)$ reaching top of the plant canopy in 1994 and 1995.

and/or quadratic coefficients were determined (Statistica for Windows, ver.5.0, StatSoft Inc., Tulsa, Okla.)

Greenhouse environment. Temperature, relative humidity and radiation inside the greenhouse were measured continuously and averaged every hour and recorded using a datalogger (DL2; Delta-T Devices, Cambridge, U.K.). Soil temperature at $0.20 \mathrm{~m}$ and air temperature at $1.5 \mathrm{~m}$ was measured using PT100 temperature sensors. Relative humidity at $1.5 \mathrm{~m}$ was measured with a hygro-thermo-transmitter sensor. Photosynthetic photonflux $(P P F)$ was measured using a quantum sensor (QS; Delta-T Devices) located at the top of the plant canopy.
Temperature, irradiation and phenology. Growing degree-days (GDD) were calculated using a base temperature of $5^{\circ} \mathrm{C}$ (Hoover et al. 1989). Phenology was determined by biweekly observations of all cane tips in each plot. The date of the onset of the first flower bud (cessation of vegetative growth), fruit set (petal fall) and the first fruit harvested was recorded. For each density treatment the percentage of canes that reached each stage was calculated.

Canopy light microclimate/leaf area/photosynthesis. To quantify the canopy light microclimate at the different cane densities we measured the intercepted PAR fraction $(f)$ at four heights $(0,40,80$ and $120 \mathrm{~cm})$ at flowering using a ceptometer (SF-40; Delta-T Devices). The intercepted fraction $(f)$ was determined using the following equation (accordingly to the ceptometer manufacturer): $f=1-\mathrm{t}-\mathrm{r}-(\mathrm{t} \mathrm{rs})$, where $\mathrm{t}=\mathrm{T} / \mathrm{S}(P A R$ transmitted by canopy $/ P A R$ at top of canopy); $\mathrm{r}=\mathrm{R} / \mathrm{S}$ ( $P A R$ reflected by canopy/PAR at top of canopy); and rs = U/T (PAR reflected at soil level/PAR transmitted at soil level)

Sunfleck (direct solar radiation that penetrates through gaps in the canopy) at the same levels, for primocanes pruned on 17 July at flowering, also was determined using the same Sunfleck ceptometer. All measurements were made with sensors positioned horizontally along the canopy (within the hedgerow) at solar noon under clear skies.

Leaf area per cane was measured using a leaf area meter (Mark2; Delta-T Devices, Cambridge, England) on four canes in each density treatment.Carbon dioxide assimilation rate, $\mathrm{A}\left(\mu \mathrm{mol} \cdot \mathrm{m}^{-2} \cdot \mathrm{s}^{-1}\right)$ was determined using a portable gas exchange system (LCA-3; Analytical Development and Co Ltd., Hertfordshire, U.K.) equipped with a Parkinson broadleaf chamber and operated as an open system. All measurements were made between two and three hours after sunrise (0930 and $1030 \mathrm{HR}$ ) to avoid any diurnal effect. Eight randomly selected fully-expanded leaves of different canes were chosen at the seven to the eighth node position (counted from the tip) for each treatment Measurements were taken at the upper surface

Table 1. Effect of pruning date and cane density on growth and fruiting characteristics, yield, and primocane yield efficiency in 1994 and 1995

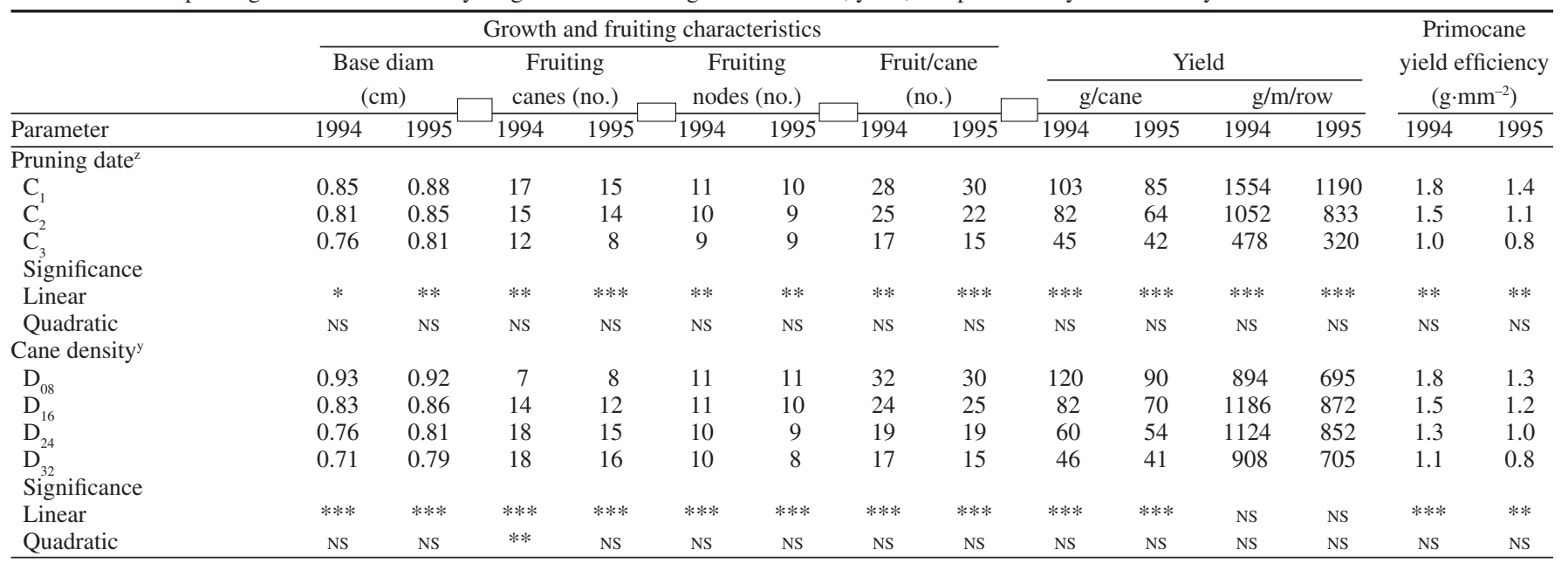

${ }^{2}$ Canes pruned on 1 to 3 July, 15 to 17 July, and 29 to 31 July $\left(C_{1}, C_{2}\right.$, and $C_{3}$, respectively) for 1994 and 1995 experiment.

${ }^{y}$ Densities adjusted to $8,16,24$, and 32 canes per meter row $\left(\mathrm{D}_{08}, \mathrm{D}_{16}, \mathrm{D}_{24}\right.$, and $\mathrm{D}_{32}$, respectively).

'Densities adjusted to $8,16,24$, and 32 canes per meter row $\left(\mathrm{D}_{08}, \mathrm{D}_{16}, \mathrm{D}_{24}\right.$,
${ }_{\text {ns, }, * * * * *}$ Nonsignificant, significant at $P \leq 0.05,0.01$, or 0.001 , respectively.

HortScience Vol. 39(3) June 2004 


\section{Crop Production}

of each leaf, one minute after the chamber had been closed and stability had been reached Assimilation rate was measured in 1995 after $50 \mathrm{~d}$ of growth at all pruning dates and densities and at primocanes pruned on 3 July on three different dates (22 Aug., 7 Oct., and 17 Oct.) from vegetative growth to flowering. Assimilation throughout the canopy was also measured $80 \mathrm{~d}$ after pruning for cane density treatments with 8 and 24 canes per meter row pruned on 3 July 1995. For light-response curves a series of five neutral-density filters were sequentially placed above the leaf chamber to reduce $P P F$. A black plastic bag was placed over the leaf chamber to measure response with no light. Each shade treatment was imposed $15 \mathrm{~min}$ before the measurement was taken (Fernandez and Pritts, 1994). Readings were taken on eight canes of cane density treatments 8 and 24 pruned on 3 July 1995 (90 d after pruning).

Drymatteraccumulation. To study dry matter accumulation all above ground biomass (canes and leaves cut at end of harvest) was dried in an oven (Memmert, Schwabach, Germany) set at $70{ }^{\circ} \mathrm{C}$ and maintained until samples reached a constant weight. Mean fruit dry mass was determined from $100 \mathrm{~g}$ of fully ripe fruit, sampled randomly twice a week during all harvest periods, and yield transformed accordingly. Harvestindex was calculated only on above ground dry mass (fruit mass)/(cane + leaves + fruit mass).

\section{Results and Discussion}

Growth characteristics and yield. Yield decreased linearly with later pruning dates both per cane and per meter row basis (Table 1). With cane densities yields per cane decreased linearly and yield per length of row was maximized between 16 to 24 canes per meter row (Table 1 ).

Pruning date did not significantly affect mean cane length ( 215 and $195 \mathrm{~cm}$ for 1994 and 1995 respectively) but later pruning decreased basal cane diameter especially in 1994 (Table 1). On all pruning dates, increasing cane density significantly decreased cane length and basal diameter (Table 1), presumably due to higher competition for resources among canes (Crandall et al., 1974).

Fruiting cane number steadily decreased with a delay in pruning in 1994. Early July pruning with up to $85 \%$ canes fruiting in $\mathrm{C}$ compared with $60 \%$ of canes fruiting in $\mathrm{C}_{3}$ (Table 1). Fruiting nodes and fruit number per cane was higher in $\mathrm{C}_{1}$ and $\mathrm{C}_{2}$ than in $\mathrm{C}_{3}$. The combination of these factors contributed to the sharp decrease in yield per cane for the third pruning date (Table 1). The drastic drop observed in yield per cane of $\mathrm{D}_{08}$ in $\mathrm{C}_{3}$ explains the significant $\mathrm{C} \times \mathrm{D}$ interaction.

In 1995 , fruiting cane number was higher in $\mathrm{C}_{1}$ and $\mathrm{C}_{2}$ than $\mathrm{C}_{3}$, and exhibited a significant interaction with cane density (Table 1). Node and fruit numbers per cane were also higher for $\mathrm{C}_{1}$. Differences in yield per cane were related to cane vigor, which may be responsible for the density effect (Table 1). Smaller proportion of fruiting canes and fewer fruits per cane led to poor fruiting conditions probably responsible for the observed linear reduction in yield per meter row. Primocane yield efficiency declined with pruning date and cane density treatment also demonstrates this assumption.

Phenology, temperature and irradiation. Late pruning delayed the onset of all phenological stages (Fig. 2 I, II, and III). The reduction in the percentage of canes that reached first flower was greater in 1995 than in 1994 (Fig. 2 Ia and Fig. 2 Ib, respectively). In 1994, the number of days to first harvested fruit was similar for $\mathrm{C}_{2}$ and $\mathrm{C}_{3}$ but different for $\mathrm{C}_{1}$ (Fig. 2 IIIa). In 1995, the $\mathrm{C}_{3}$ treatment fruited later than the other two pruning dates (Fig. 2 IIIJ). Flower differentiation was severely affected as cane density increased and as pruning date was delayed. In the 1995 experiment, only $27 \%$ of $\mathrm{D}_{32}$ canes in the $\mathrm{C}_{3}$ treatment had differentiated flowers after $103 \mathrm{~d}$ (Fig. $2 \mathrm{Ib}$ ). Accordingly we observed fewer fruiting canes because thinner canes in higher densities are slower to initiate primocanes flowers.

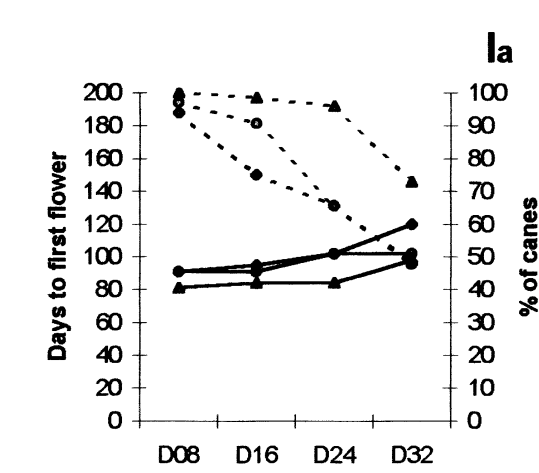

Yield differences were likely due to differential levels of light and air temperature. Hoover et al. (1989) observed that higher air temperatures encouraged early flowering and promoted more flowering nodes, but they were not able to associate differences with growing degree-days (GDD). Lockshin and Elfving (1981) reported that high air temperature induces early flowering, but flowering began when plants reached the 24- to 25-node stage, regardless of temperature. In our experiment, GDD increased with the date of pruning until first flower stage, and than decreased from first flower to end of harvest. In 1995 GDD was higher from pruning to harvest than in 1994, reaching 2900 GDD. The inverse relationship between GDD and yield, indicates that air temperature is not the only factor influencing yield, although temperature effect is always present since it is the most complex and integrates all processes (Lakso, 1994).

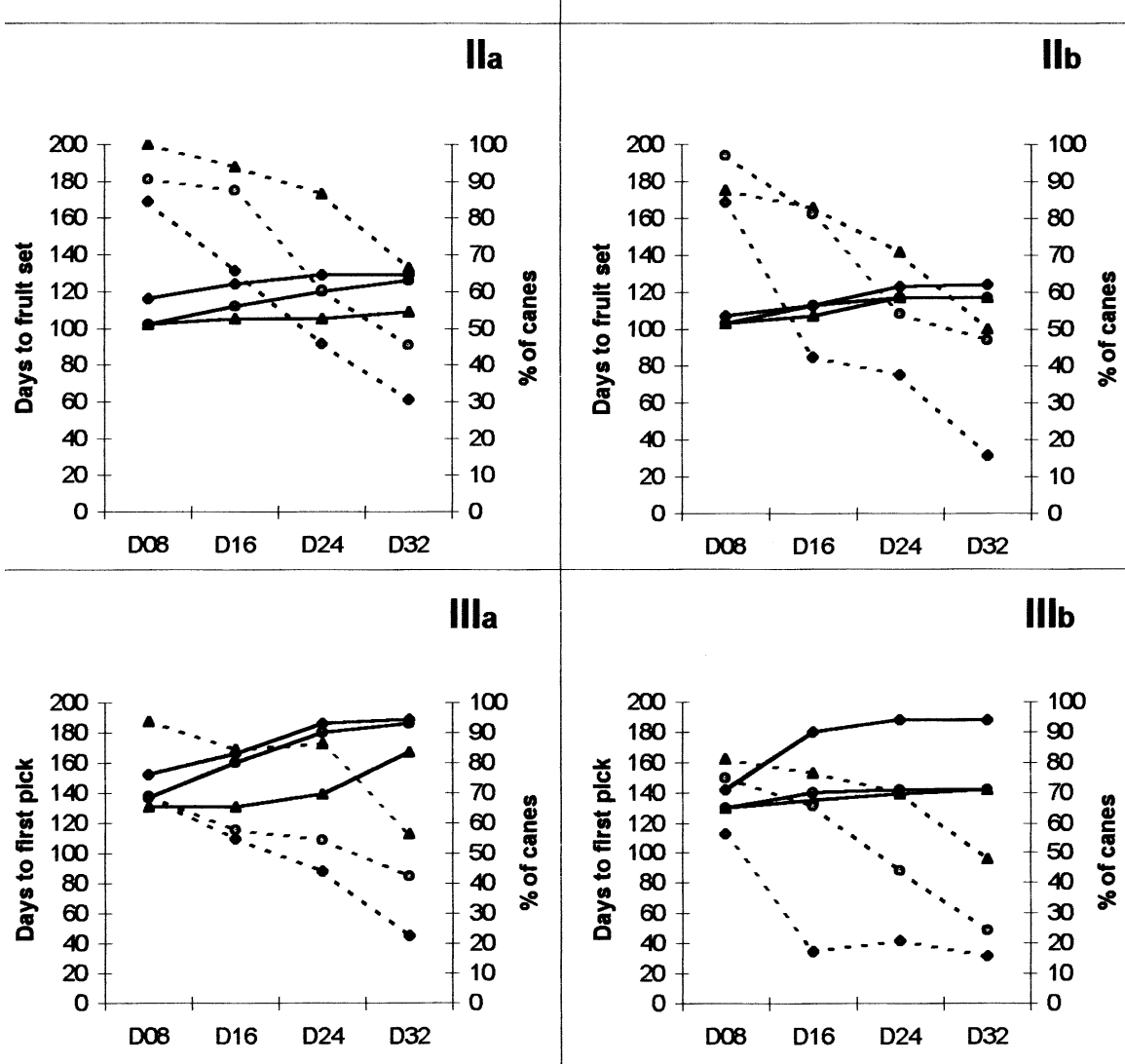

Fig. 2. Effect of cane density $\left(8,16,24\right.$, and 32 canes per meter row; $\mathrm{D}_{0}, \mathrm{D}_{1}, \mathrm{D}_{2}$, and $\mathrm{D}_{32}$, respectively) and pruning date $(\Delta)$ first, $1 / 3$ July; $(0)$ second 15 and 17 and $(\diamond)$ third, 29 and 31 July) on the number of days (-) to first flower (I), days to fruit set (II), and days to first harvested fruit (III), with the corresponding percentage of canes that reached that stage (---), in 1994 (a) and 1995 (b) 

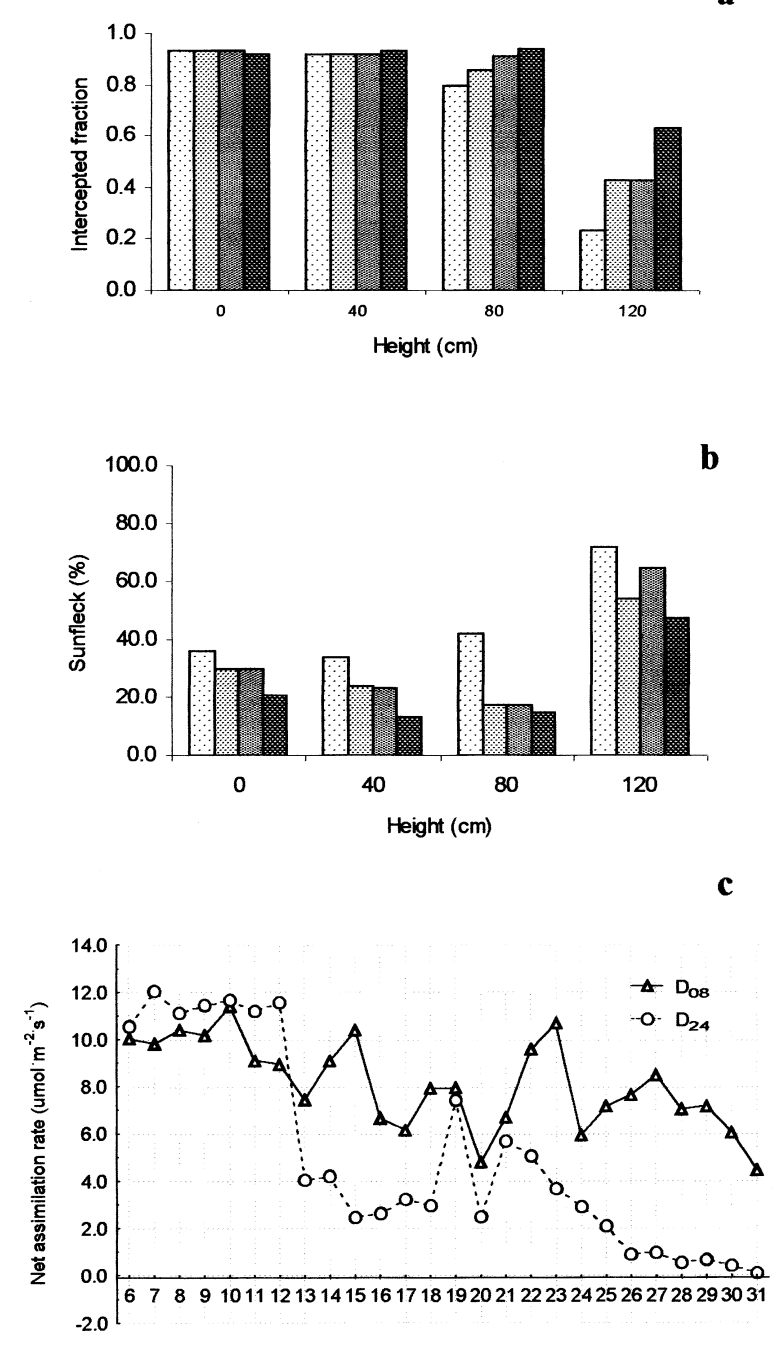

Leaf position (from top)

Fig. 3. Density effect on light microclimate within the canopy (at ground level, 40, 80, and $120 \mathrm{~cm}$ height) in 1995, for plants pruned on 17 July measured at flowering: (a) intercepted PAR fraction, (b) sunfleck (\%). (c) Net $\mathrm{CO}_{2}$ assimilation rate of leaves (6 to 31 ; from top to bottom) of canes of density treatments 8 and 24 canes per meter row $\left(D_{08}\right.$ and $D_{24}$, respectively) for first pruning date ( 3 July) measured at flowering.

Photosynthetic photon flux was higher in 1994 than in 1995 (for the period between pruning and first flower). In primocane fruiting cultivars we assume that the critical period for flower induction begins at the moment when terminal bud changes from a vegetative state to flowering. From first flower to end of harvest a high correlation between yield per cane and accumulated $P P F$ was obtained $\left(r^{2}=0.62\right.$ for $P<0.01)$. Although the correlation coefficient between $P P F$ and yield was highly significant, it does not prove a causal relationship between these variables.

Canopy light microclimate, leaf area, and photosynthesis. The intercepted light measured for $\mathrm{C}_{2}$ in 1995 at flowering was similar at ground level and at the 40-cm height at all densities, but above $80 \mathrm{~cm}$, less radiation was intercepted on $\mathrm{D}_{08}$ (Fig. 3a). Sunflecks were also higher c

a for $\mathrm{D}_{08}$ with an increase after 80 $0 \mathrm{~cm}$ (Fig. 3b) indicating a higher percentage of the canopy was illuminated. Leaf area per cane was higher at $\mathrm{D}_{08}$ indicating that plants responded to more available space.

Rate of leaf photosynthesis was not significantly different for all cane densities $(9.4$ $\left.\mu \mathrm{mol} \cdot \mathrm{m}^{-2} \cdot \mathrm{s}^{-1}\right)$ during active vegetative growth, even across radiation levels. Assimilation rates for $\mathrm{C}_{1}$ and $\mathrm{C}_{3}$ were similar $\left(10.2 \mu \mathrm{mol} \cdot \mathrm{m}^{-2} \cdot \mathrm{s}^{-1}\right)$ at PAR of 580 to $760 \mu \mathrm{mol} \cdot \mathrm{m}^{-2} \cdot \mathrm{s}^{-1}$, but were significantly higher than $\mathrm{C}_{2}$ $\left(7.9 \mu \mathrm{mol} \cdot \mathrm{m}^{-2} \cdot \mathrm{s}^{-1}\right)$ at $P A R$ levels from 398 to $490 \mu \mathrm{mol} \cdot \mathrm{m}^{-2} \cdot \mathrm{s}^{-1}$. Leaf temperature was between 26 and $32^{\circ} \mathrm{C}$ in all three pruning date measurements. Net $\mathrm{CO}_{2}$ assimilation rate also was constant and equal for all cane densities $\left(10.0 \mu \mathrm{mol} \cdot \mathrm{m}^{-2} \cdot \mathrm{s}^{-1}\right)$ from vegetative growth to flowering $(50,95$, and $105 \mathrm{~d}$ after $\mathrm{C}_{1}$ ). Primocanes appeared sensitive to high temperature with a dramatic drop in A when leaf temperature was $>34{ }^{\circ} \mathrm{C}$, which agrees with the results presented by Fernandez and Pritts (1994).

At the first pruning date, $\mathrm{D}_{08}$ had significantly higher value of A throughout the canopy than $\mathrm{D}_{24}$ (Fig. 3c). $\mathrm{D}_{24}$ exhibited a significantly higher value of $A$ from leaf 6 to leaf 12 , a compensatory effect similar to that observed by Cameron and Hartley (1989) when they partially defoliated 'Amity' red raspberry canes. Since available light below 80 $\mathrm{cm}$ is near zero (about leaf 20), A value is strongly reduced for $\mathrm{D}_{24}$ but not for $\mathrm{D}_{08}$. Light response curves for $\mathrm{D}_{08}$ and $\mathrm{D}_{24}$ were similar, but $\mathrm{D}_{24} \mathrm{~A}$ values were higher at lower $P P F$ (Fig. 4). $D_{24}$ had a higher acclimation to the lower light level than $\mathrm{D}_{08}$, but $\mathrm{D}_{08}$ assimilation is higher throughout the cane due to a better overall light microclimate.

Dry matter accumulation. Total above ground dry weight accumulation per meter row significantly decreased with pruning date and increased with cane density (Fig. 5). The sharp decrease in harvest index indicates that yield was more severely imposed by cane density than above ground dry weight in all three pruning dates (Fig. 5a). Above ground dry weight per meter row increased with cane density (Fig. 5b). Cane and leaf dry weight increased with increasing cane density with a significant quadratic response in 1994 and a linear response in 1995 (data not shown).

Fernandez and Pritts (1993) reported that the root system is a competitive sink for carbohydrates due to active root growth during fruiting. A strong root sink could reduce carbohydrate availability at all three pruning dates, reducing above ground dry mass. Our results sugges that raspberry is a source-limited plant and fruit might be a weaker sink compared to the root system. Reduced allocation of carbohydrates to fruits also could be associated with the age of the planting. Whitney (1982) proposed that raspberries favored vegetative growth over fruiting in the first years, but that after several years plants began shifting more resources to seed production (fruits)

We did observe a significant decrease in yield per cane with increasing cane density, which agrees with previous research (Heuvel et al., 2000; Myers, 1993; Oydvin, 1986). Yield per meter row was consistent across changing cane density as previously reported by Buszard (1986). Despite the decline in primocane yield with pruning date and density, this experiment indicates that 16 to 24 canes per meter row was the optimal number of canes for all pruning dates and years. Dale (1989) hypothesized that in summer-fruiting raspberries 6 to 8 fruiting canes give the optimum yield. Since in fallfruiting canes we only have one type off canes it seems that there is an optimum cane density that maximizes yield regardless of raspberry fruiting habit.

Temperature ranged between 20 to $30^{\circ} \mathrm{C}$

Fig. 4. Light response curve for leaves (7 to 8 ) on canes of density treatments 8 and 24 canes per meter row $\left(\mathrm{D}_{08}\right.$ and $\mathrm{D}_{24}$ respectively) of first pruning date (3 July) during flowering. Lea temperature varied between 24 and $30^{\circ} \mathrm{C}$ during all measurements.
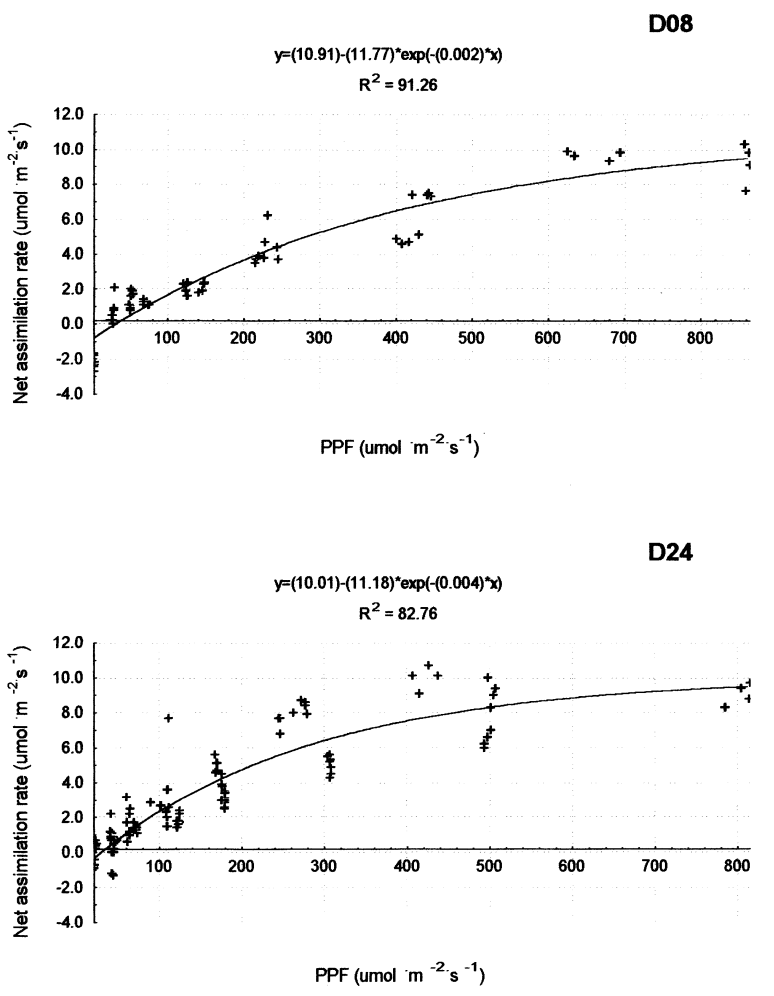
I-a

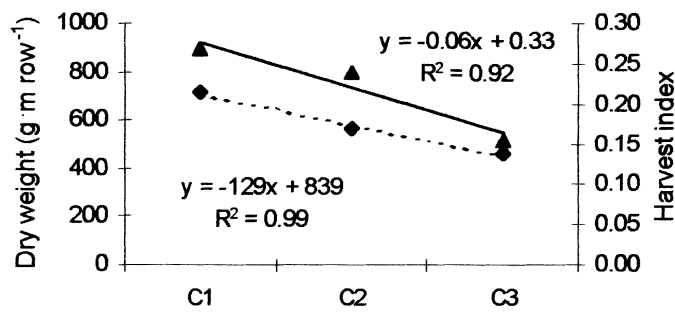

I-b
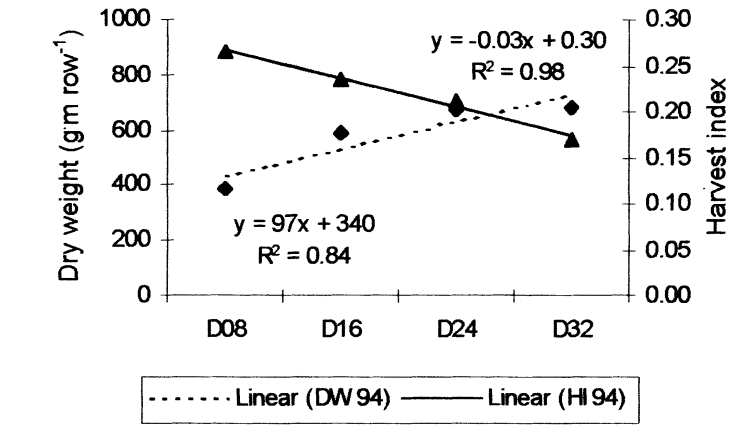

II-a

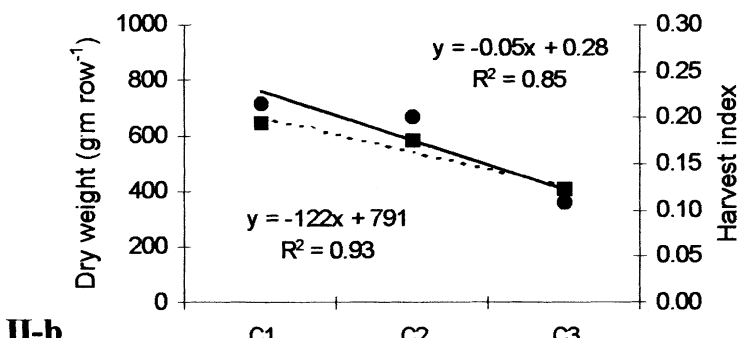

$\mathbf{I}-\mathbf{b}$

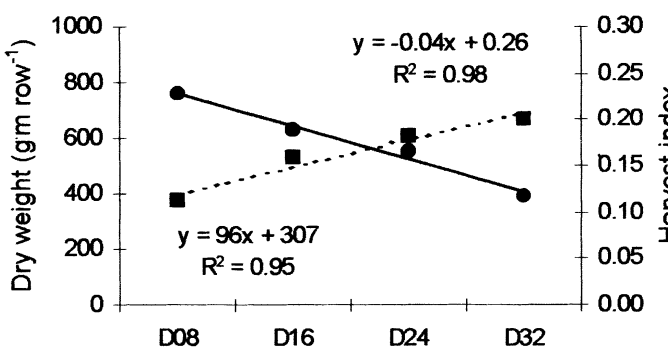

... . Linear (DW 95) — L Linear (H 95)
Braun, J.W. and J.K.L. Garth. 1984. irrigation, and carbohydrate reserves on Amer. Soc. Hort. Sci. 99:524-526. involving British and Pacific Northwest

Fig. 5. Above ground dry weight (Dw) and harvest index $(\mathrm{HI})$ for (a) pruning dates (canes pruned on 1 and 3,15 and 17 and 29 and 31 July $\left(\mathrm{C}_{1}, \mathrm{C}_{2}\right.$. and $\mathrm{C}_{3}$, respectively) for 1994-95 experiment) and (b) cane densities $(8,16,24$, and 32 canes per meter row, $\mathrm{D}_{0}, \mathrm{D}_{16}, \mathrm{D}_{2}$, and $\mathrm{D}_{32}$, respectively), in 1994 (I) and 1995 (II) experiments.

from flower bud differentiation until the end of harvest. Since assimilation rate in 'Autumn Bliss' is not affected by air temperature until $30^{\circ} \mathrm{C}$ (Stafne et al., 2001), we can assume that $P P F$ was the most important climatic factor
119:1163-116

limiting plant productivity across our treatments. To better understand the relationship between light and yield, a more precise experiment must be delineated. We hypothesize that under low light conditions, current yield is reduced, although accumulation of carbohydrates in the root system for next year's growth is maintained. In further research the role of carbohydrate reserves on raspberry productivity should be considered, along with the relationship between light intensity and the number of laterals and fruits per lateral.

\section{Literature Cited} Intracane yield compensation in the red raspberry. J.Amer.Soc.Hort.Sci. 109:526-530.

Buszard, D.J. 1986. The effect of management system on winter survival and yield of raspberry in Quebec. Acta Hort. 183:175-181.

Cameron, J.S. and C.A. Hartley. 1989. The influence of leaf/fruit ratio on gas exchange characteristics of red raspberry leaves. Acta Hort. 262:255-258. Crandall, P. . D.F. Allmendinger J.D. Cham 1974. Cha Influence of canenus Bider the fruit number of red raspberries.

Dale, A. and H.A. Daubeny. 1985 Genotype-environment interactions red raspberry cultivars. HortScience 20:68-69.

Dale, A. and H.A. Daubeny. 1987. Flower-bud initiation in the red raspberry (Rubus idaeus L.) in two environments. Crop Res. 27:61-66.

Dale, A. 1989. Productivity in the red raspberries. Hort. Rev. 11:185-228.

Fernandez, G.E. and M.P. Pritts. 1993. Growth and source-sink relationships in 'Titan' red raspberry. Acta Hort. 352:151-157.

Fernandez, G.E. and M.P. Pritts 1994. Growth, carbon acquisition, and ource-sink relationships in 'Titan' ed raspberry. J. Amer. Soc. Hort. Sci.

n harvest date and cane development of primocanefruiting red raspberries. Acta Hort. 262:297-303.

Hudson, J.P. 1958. Effects of weather on plant behaviour. Nature 182:1337-1340

Lakso, A.N. 1994. Apple, p. 3-42. In: B. Schaffer and P.C. Andersen (eds.). Handbook of environmental physiology of fruit crops. vol. 1. Temperate crops. CRC Press, Boca Raton, Fla.

Lockshin, L.S. and D.C. Elfving. 1981. Flowering response of 'Heritage' red raspberry to temperature and nitrogen. HortScience 16.527-528.

Monteiro, A.A. and C.M. Portas. 1986. Mild winter concept and cropping systems in solanacea protected cultivation. Acta Hort. 191:21-34

Myers, S.C. 1993. Primocane development and early yield of 'Heritage' red raspberry in relation to initial plant in-row spacing. J. Amer. Soc. Hort. Sci. 118:6-11

Oliveira, P.B., C.M. Oliveira, L. Lopes-da-Fonseca, and A.A. Monteiro. 1996. Off-season production of primocane-fruiting red raspberry using summer pruning and polyethylene tunnels. HortScience 31:805-807.

Oliveira, P.B., C.M. Oliveira, P.V. Machado, L. Lopesda-Fonseca, and A.A. Monteiro. 1998. Improving off-season production of primocane-fruiting red raspberry by altering summer-pruning intensity. HortScience 33:31-33.

Oliveira, P.B., C.M. Oliveira, L. Lopes-da-Fonseca, and A.A. Monteiro. 1999. Summer-pruning intensity affects on off-season production of primocane-fruiting red raspberries. Acta Hort. 505:101-105.

Oliveira, P.B., L. Lopes-da-Fonseca, and A.A. Monteiro. 2002. Combining different growing techniques for all year round red raspberry production in Portugal. Acta Hort. 585:545-553.

Oydvin J. 1986. The Gjerde method for training raspberries. Effects of increasing cane number and cane height. Acta Hort. 183:173-174.

Percival, D.C., J.T.A. Proctor, and M.J. Tsujita. 1996 Whole-plant net $\mathrm{CO}_{2}$ exchange of raspberry as influenced by air and root-zone temperature, $\mathrm{CO}_{2}$ concentration, irradiation and humidity. J. Amer. Soc. Hort. Sci. 121:838-845.

Percival, D.C. J.T. A. Proctor, and J.A. Sullivan. 1998. Supplementary irrigation and mulch benefit the establishment of 'Heritage' primocane-fruiting raspberry. J. Amer. Soc. Hort. Sci. 123:518-523.

Popenoe, J. 1994. Dry weight partitioning in three phenotypes of red raspberry. J. Amer. Soc. Hort. Sci. 119:940-942.

Privé, J.P., J.A. Sullivan, J.T.A. Proctor, and O.B. Allen. 1993a. Performance of three primocane-fruiting red raspberry cultivars in Ontario and Québec. J. Amer. raspberry cultivars in Ontario

Privé, J.P., J.A. Sullivan, J.T.A. Proctor, and O.B. Allen. 1993b. Climate influences vegetative and reproductive components of primocane-fruiting red raspberry cultivars. J. Amer. Soc. Hort. Sci. 118:393-399.

Stafne, E.T., J.R. Clark, and C.R. Rom. 2001. Leaf gas exchange response of 'Arapaho' blackberry and six red raspberry cultivars to moderate and high temperatures. HortScience 36:880-883.

Trinka, D.L. and M.P. Pritts. 1992. Micropropagated raspberry plant establishment responds to weed control practices, row cover use, and fertilizer placement. J. Amer. Soc. Hort. Sci. 117:874-880. reduction has a minimal influence on current year's red raspberry (Rubus idaeus L.) fruit production. J. Amer. Soc. Hort. Sci. 121:473-477.

Heuvel, J.E.V., J.A. Sullivan, and J.T.A. Proctor. 2000. Trellising system and cane density affect yield and fruit quality of red raspberry. HortScience 35:1215-1219.

Hoover, E., J. Luby, and D. Bedford. 1988. Vegetative and reproductive yield components of primocanefruiting red raspberries. J. Amer. Soc. Hort. Sci. 113:824-826

Hoover, E., J. Luby, D. Bedford, M. Pritts, E. Hanson, A. Dale, and H. Daubeny. 1989. Temperature influence

Whitney, G.G. 1982. The productivity and carbohydrate economy of a developing stand of Rubusidaeus. Can. J. Bot. 60:2697-2703.

Williams, I.H. 1959. Effects of environment on Rubus idaeus L. IV. Flower initiation and development of the inflorescence. J. Hort. Sci. 34:219-228.

Wright, C.J. and P.D. Waister. 1982. Within-plant competition in the red raspberry. II. Fruiting cane growth. J. Hort. Sci. 57:443-448. 